\title{
ASSESSMENT OF FEASIBILITY AND COMPLICATIONS OF LAPAROSCOPIC CHOLECYSTECTOMY IN CIRRHOTIC PATIENTS
}

\section{ANSHUMAN PANDEY, NITIN GOYAL, SHAKEEL MASOOD, SMITA CHAUHAN, ALANKAR GUPTA, KHALID NOMAN}

Department of Surgical Gastroenterology, Dr. Ram Manohar Lohia Institute of Medical Sciences, Lucknow, India. Email:

Received: 14 February 2017, Revised and Accepted: 14 April 2017

\begin{abstract}
Introduction: From the era of absolute contraindication to the phase of preferred treatment, the technique of laparoscopic cholecystectomy advances with time. Here, we report our experience of laparoscopic cholecystectomy in 20 patients with liver cirrhosis. In our institute, laparoscopic
\end{abstract} cholecystectomy is the preferred choice for cholelithiasis in cirrhotic patient.

Methods: In past 2 years, 180 laparoscopic cholecystectomies were performed and 20 patients were cirrhotic. Their data analyzed retrospectively in terms of pre-operative optimization, operative technique and results.

Results: Laparoscopic cholecystectomy was completed successfully in 19 patients and one was converted to open. Mean operative time was 54 minutes. No additional port was required in all cases. Calot's first dissection was performed in 18 patients and fundus first technique was used in two patients due to unclear anatomy. Liver bed bleeding was present in 16 patients, which was controlled effectively. Subhepatic drain was placed in 12 patients. There was no mortality. Morbidity in two patients was worsening of ascites in one; incisional hernia in other patient which was converted to open. Port site complications were not noted in any patient, and there was no evidence of intraabdominal bleeding or bile leak postoperatively. Blood and component transfusion was required in two patients. Average length of hospital stay was 4.8 days.

Conclusion: Although laparoscopic cholecystectomy may be difficult in cirrhotic patients, it is feasible and relatively safe. It offers many advantages in cirrhotic patients and associated with low morbidity when compared with open surgery.

Keywords: Cirrhosis, Laparoscopic cholecystectomy, Difficult cholecystectomy.

(C) 2017 The Authors. Published by Innovare Academic Sciences Pvt Ltd. This is an open access article under the CC BY license (http://creativecommons. org/licenses/by/4. 0/) DOI: http://dx.doi.org/10.22159/ajpcr.2017.v10i7.17722

\section{INTRODUCTION}

Surgery in liver cirrhosis is a complex issue as the result is dependent on multiple factors. There are many operative indications and cholelithiasis is one of the more common indications. This is more so as it is twice as common in cirrhotic as compared to the population [1,2]. Any operation in decompensated liver disease is associated with increased post-operative morbidity mainly because of increased chance of hemorrhage and worsening of liver function, which may also lead to liver failure. Mortality in cirrhotic patients is as high as 20 times more in comparison with non-cirrhotic patients [3]. Therefore, surgery in a cirrhotic patient is a challenging scenario. However at times, it becomes necessary to treat patient having cholelithiasis with cirrhosis due to debilitating symptoms [4]. Although around $30 \%$ of cirrhotic patients are having cholelithiasis, most of them are asymptomatic and may not warrant surgery [5]. Laparoscopic cholecystectomy is the surgical treatment of choice for cholelithiasis. Since early 1990's, when it was first introduced, it has evolved into a safe and patient friendly procedure. Initially pregnancy, previous abdominal surgery, obesity, cirrhosis, and acute cholecystitis were considered absolute contraindications for a laparoscopic approach [6]. However, with improved vision, instruments and increasing experience with laparoscopic surgeries more and more surgeries are being done laparoscopically. The use of harmonic scalpel, vessel sealing devices, argon plasma coagulation, etc., has made laparoscopic cholecystectomy the preferred procedure in all these patients $[7,8]$. Several studies reported positive results and have suggested laparoscopic cholecystectomy, as the first choice, in cirrhotic patients with cholelithiasis $[9,10]$. In this study, we report our experience of laparoscopic cholecystectomy in the cirrhotic patients.

\section{METHODS}

The study was performed at Dr. Ram Manohar Lohia Institute of Medical Sciences, Lucknow, India, which is a tertiary care center. Over the past 2 years, 180 laparoscopic cholecystectomies were performed for symptomatic cholelithiasis, and their data were retrospectively analyzed. 20 patients were cirrhotic and included in our study. The preoperative optimization, operative technique, and results were analyzed. The diagnosis of cholelithiasis was based on clinical findings and confirmed by abdominal sonography. The diagnosis of cirrhosis was made based on history, laboratory investigations and sonographical evaluation. Specific tests such as endoscopy to rule out varices, preoperative fibroscan, or liver biopsy were done in selected cases in consultation with medical gastroenterology. All surgeries were done in elective setting after optimization; all the patients were in Child's A class at the time of surgery. The procedure was performed by same surgical team in similar setting. The patient demographics and preoperative assessment were noted in Table 1.

A standard operative technique with four ports was followed in each patient. Pneumoperitoneum was created by closedveress needle insertion infraumblically and converted to $5 \mathrm{~mm}$ port. Care was taken to avoid injury to periumblical collaterals in case seen. Epigastric port (10 $\mathrm{mm}$ ) was inserted slight right to midline to avoid injury to falciform ligament. Two other ports $(5 \mathrm{~mm})$ were placed for dissection and retraction. Adhesiolysis was done with care. In case of cirrhotic patients harmonic scalpel or vessel sealer ( $\mathrm{N}$ seal) was used for dissection of collaterals. Dissection within the Calot's triangle was done similarly and gauze compression was used to stop minor ooze. Critical view of safety was assessed similarly in each case. Cystic artery was approached with clips or hemolok depending on the caliber. Cystic duct was approached 
similarly. In case the Calot's anatomy was unclear; a fundus first dissection was done. Gall bladder was separated from liver bed using monopolar cautery or harmonic scalpel depending on the collaterals. Argon plasma coagulation was used at gall bladder bed in case of ooze. Liver wedge biopsy was done in each case from a suitable area in all cirrhotic patients with adequate hemostasis. Subhepatic drain was placed in case general ooze was there and hemostasis was a concern. All port sites were closed precisely to prevent post-operative ascites leak which might cause wound infection and peritonitis.

Intraoperative assessment (Table 2)

\section{Post-operative assessment (Table 3)}

\section{RESULT}

During 2 years of the study period, 180 laparoscopic cholecystectomy procedures were performed and out of which 20 cirrhotic patients with cholelithiasis underwent laparoscopic cholecystectomy. The procedure was completed laparoscopically in 19 patients and one was converted to open. Mean operative time was 54 minutes. No additional port was

\section{Table 1: Patient's demographic and pre-operative assessment}

\begin{tabular}{ll}
\hline Total no of patients & 20 \\
M:F & $3: 2$ \\
Age range & $35-65$ years \\
Mean age & 57 years \\
Indication of surgery & Chronic cholecystitis-18 \\
& Acute cholecystitis-2 \\
Cause of cirrhosis & Hepatitis B-3 \\
& Hepatitis C-4 \\
& Alcohol-3 \\
Previous abdominal surgery & (NASH)-8 \\
CTP class & 4 patients \\
MELD score & A in all patients \\
Pre-operative ascites & 6 in all patients \\
\hline
\end{tabular}

NASH: Non-alcoholic steatohepatitis, CTP: ???, MELD:

Table 2: Intraoperative assessment

\begin{tabular}{|c|c|}
\hline Pressure of pneumoperitoneum & $10 \mathrm{~mm} \mathrm{Hg}$ \\
\hline Technique of port placement & Standard 4 port technique \\
\hline Requirement of additional port & No \\
\hline Conversion to open & One \\
\hline Technique of dissection & Calot's first - 18 \\
\hline Critical view of safety & $\begin{array}{l}\text { Fundus first - } 2 \\
\text { Assessed in all patients before } \\
\text { clipping }\end{array}$ \\
\hline Intraoperative liver bed oozing & In 16 patients \\
\hline Omentum adhered to GB & In 16 patients \\
\hline $\begin{array}{l}\text { Requirement of hemostatic } \\
\text { devices (harmonic/APC) }\end{array}$ & In all patients \\
\hline Placement of subhepatic drain & In 12 patients \\
\hline Mean operative time & 54 minutes \\
\hline
\end{tabular}

Table 3: Post-operative assessment

Port site bleeding

Evidence of intraabdominal bleeding

Worsening of ascites

Port site infection

Evidence of bile leak

Requirement of blood products

Mean length of hospital stay

Incisional hernia required in all cases. Calot's first dissection technique was used in 18 patients, and fundus first technique was used in two patients due to unclear anatomy. Critical view of safety was assessed in all patients. None of the patients have significant ascites detected intraoperatively. Liver bed bleeding was present in 16 patients, which was controlled with electrocautery and argon plasma coagulation. Subhepatic drain was

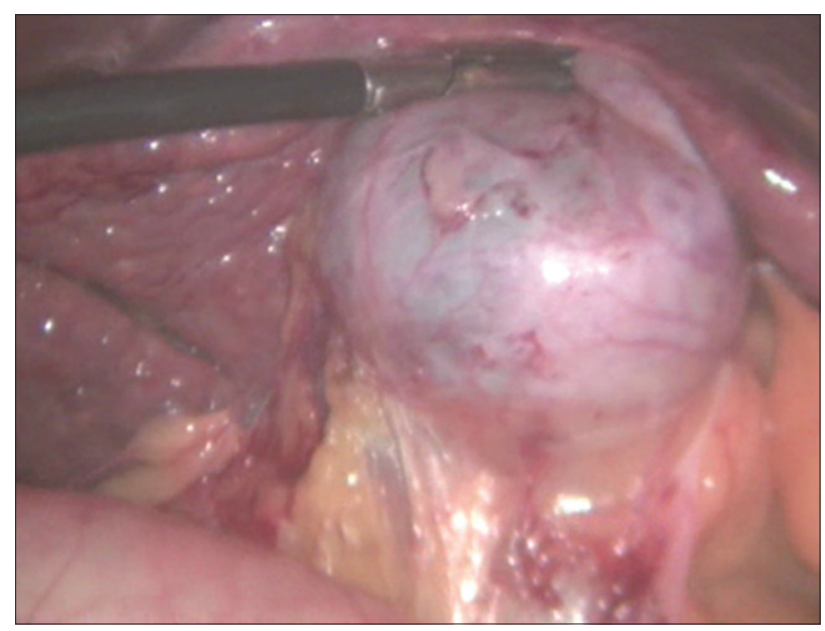

Fig. 1: Laparoscopic view of gall bladder with cirrhotic liver

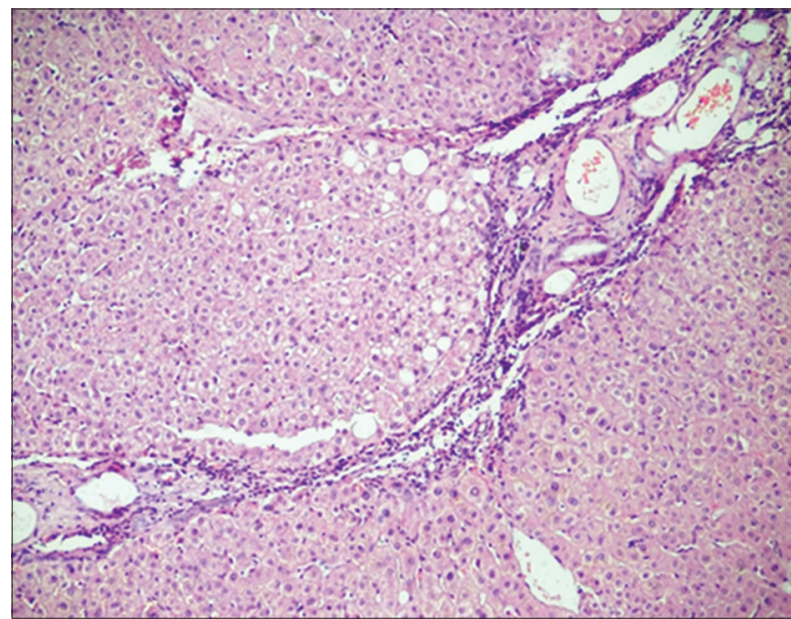

Fig. 2: Regenerative nodules in cirrhosis showing thick liver plates $(\mathrm{H}$ and $\mathrm{E} \times \mathbf{1 0 0})$

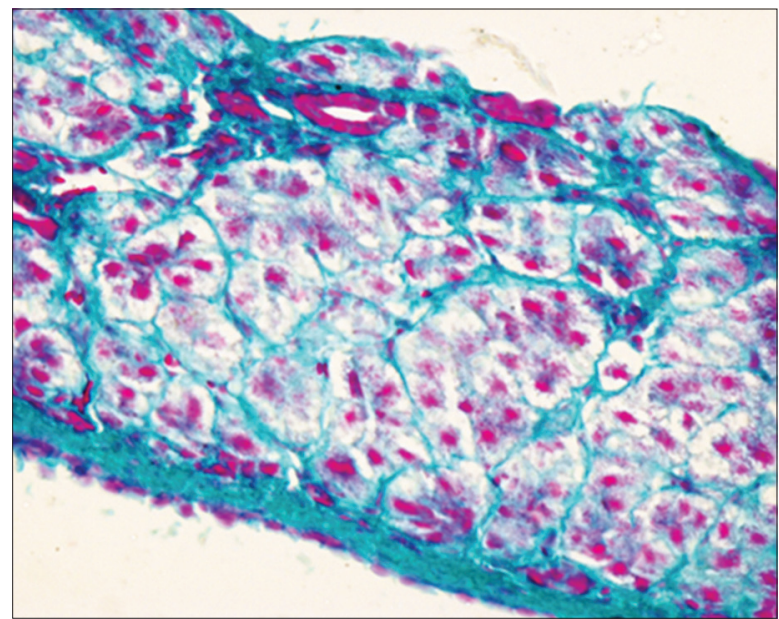

Fig.3: Regenerativenodulesincirrhosiswithseptal fibrosis(MT ×400) 
placed in 12 patients. There was no mortality. Morbidity in two patients was worsening of ascites in one, which was managed conservatively and incisional hernia in other. Port site complications were not noted in any patient, and there was no evidence of intraabdominal bleeding or bile leak postoperatively. Blood and component transfusion was required in two patients. Average length of hospital stay was 4.8 days.

\section{DISCUSSION}

Cholelithiasis is a common disease and its prevalence is high in Indian subcontinent. Its incidence is almost twice as high in cirrhotic patients [1,2]. Various factors contribute for high incidence in cirrhotic patients are hypersplenism, hyperestrogenemia, increased intravascular hemolysis, reduction in biliary acidity with reduction in gallbladder emptying motility are cited as reasons $[11,12,13]$.

Surgery in cirrhotics is associated with high morbidity and considerable mortality. In the past, open cholecystectomy in cirrhotic patients was considered a formidable task due to poor outcomes [3]. With the advancement of surgical techniques, instruments and better pre-operative assessment and optimization, improved post-operative care, the surgical results have improved [14]. Open cholecystectomy was considered as acceptable therapeutic option. The results with laparoscopic cholecystectomy and its usefulness in cirrhotic patients were under discussion for a long time, but now various studies have documented that in child class A \& B cirrhotic patients, laparoscopic approach is safer and better tolerated [6]

Surgery should be undertaken in cirrhotic patients with symptomatic gallstone disease at an optimal time; otherwise, there is a risk of functional decompensation of liver, which has dismal outcomes. Laparoscopic cholecystectomy should be the preferred option in cirrhotic patients because of advantages such as (1) minimally invasive procedure with less morbidity and quick recovery with high patients compliance [15], (2) better magnification of view, laparoscopy is helpful to observe minute vascular channels more clearly. Portal venous collaterals and congested gall bladder bed also handled properly to reduce hemorrhagic complications [16], (3) associated with less postoperative complications such as surgical site infections, incisional hernia, and post-operative pain [17]. (4) direct contact with blood or viscera is avoided by operating team and reduces the risk of iatrogenic infections of hepatitis C virus/hepatitis C virus [18], (5) secondary bacterial peritonitis in ascitesis lesser thus reducing chances of sepsis, and (6) future liver transplantation is easier as lesser adhesions in right upper quadrant are encountered.

The possible negative aspects of laparoscopic cholecystectomy in cirrhotic patients are (1) $\mathrm{CO}_{2}$ pneumoperitoneum during laparoscopic surgery causes ischemia-reperfusion injury which may play role in post-operative liver impairment. Therefore, measures should be taken to minimize this injury in cirrhotic patients by reduction of pneumoperitoneum pressure, shortening of operative time and postoperative liver function monitoring, (2) visualization of Calot's anatomy due to atrophy-hypertrophy or displacement of liver lobes may be challenging [16].

Pneumoperitoneum and port insertion in cirrhotic patients should be done cautiously. Trocar insertion is done avoiding injury to dilated veins around umbilicus. We prefer $5 \mathrm{~mm}$ camera port infraumblically and epigastric port slight right to midline to avoid injury to falciform ligament. Lower flow rate of $\mathrm{CO}_{2}$, with intraabdominal pressure at $10-12 \mathrm{~mm} \mathrm{Hg}$ have better results. Gradual reduction of pneumoperitoneum should be the norm after the procedure [16].

Proper patient selection and optimization is necessary. Child-Pugh class provides an insight about patient's liver reserve and need for blood transfusion [19]. Child class B\&C patients should be optimized preoperatively to improve liver function by proper nutritional support, ascites control and improvement of coagulation profile [20]. It is mandatory to improve the functional status of the patient for optimal results. Upper GI endoscopy to rule out varices, fibroscan and preoperative liver biopsy may be done in specific cases. Various energy sources and vessel sealing devices help immensely during the surgery. Meticulous emphasis on surgical principles and judicious use of energy source at Calot's triangle has been of help to us. Gauze pressure in case of ooze is a better option at the Calot's triangle than extensive coagulation. Any collateral at the critical angle of safety must be tackled meticulously. Intraoperative decision of performing total or subtotal cholecystectomy, antegrade or retrograde approach to the gall bladder, leaving the posterior wall of gall bladder behind in case of extensive collaterals have all been defined and may also be done laparoscopically. All these procedures are done to avoid inadvertent massive bleeding, especially from gall bladder bed. Argon plasma coagulation is a good instrument to tackle the gall bladder bed ooze. We routinely use it apart from gauze pressure on the GB fossa with good outcomes. Routinely placing drains is controversial in all patients of cirrhosis. We usually do not place drains, but drain is placed in case adequate hemostasis is doubtful after meticulous attempt to control all ooze. There should be a low threshold for conversion to open procedure to avoid complications. In this study, one patient had conversion to open surgery due to obscured Calot's anatomy and contracted gall bladder.

\section{CONCLUSION}

Cholelithiasis in cirrhotic patients is a major health issue due to its high incidence and increased morbidity after surgical treatment. Laparoscopic cholecystectomy should be the preferred mode in cirrhotic patients. Laparoscopic cholecystectomy offers many advantages in cirrhotic patients and associated with low morbidity when compared with open surgery.

\section{REFERENCES}

1. Bouchier IA. Postmortem study of the frequency of gallstones in patients with cirrhosis of the liver. Gut 1969;10(9):705-10.

2. Nicholas P, Rinaudo PA, Conn HO. Increased incidence of cholelithiasis in Laënnec's cirrhosis. A postmortem evaluation of pathogenesis. Gastroenterology 1972;63(1):112-21.

3. Aranha GV, Sontag SJ, Greenlee HB. Cholecystectomy in cirrhotic patients: A formidable operation. Am J Surg 1982;143(1):55-60.

4. Gillet M. Chirurgie Des Voiesbiliaires Chez le Cirrhotique. Paris: AFC; 1993.

5. Conte D, Barisani D, Mandelli C, Bodini P, Borzio M, Pistoso S, et al. Cholelithiasis in cirrhosis: Analysis of 500 cases. Am J Gastroenterol 1991;86(11):1629-32.

6. Yerdel MA, Tsuge H, Mimura H, Sakagami K, Mori M, Orita K. Laparoscopic cholecystectomy in cirrhotic patients: Expanding indications. Surg Laparosc Endosc 1993;3(3):180-3.

7. Shen BY, Li HW, Chen M, Zheng MH, Zang L, Jiang SM, et al. Color Doppler ultrasonogrphic assessment of the risk of injury to major branch of the middle hepatic vein during laparoscopic cholecystectomy. Hepatobiliary Pancreat Dis Int 2003;2(1):126-30.

8. Luo D, Chen XR, Li SH, Mao JX, Yu SM. Non-image diagnosis of bile duct injury during laparoscopic cholecystectomy. Hepatobiliary Pancreat Dis Int 2002;1(1):106-10.

9. Poggio JL, Rowland CM, Gores GJ, Nagorney DM, Donohue JH. A comparison of laparoscopic and open cholecystectomy in patients with compensated cirrhosis and symptomatic gallstone disease. Surgery 2000;127(9):405-11.

10. Bloch RS, Allaben RD, Walt AJ. Cholecystectomy in patients with cirrhosis. A surgical challenge. Arch Surg 1985;120(6):669-72.

11. Dalvi AN, Deshpande AA, Doctor NH, Maydeo A, Bapat RD. Laparoscopic cholecystectomy in patients with portal cavernoma and portal hypertension. Indian J Gastroenterol 2001;20(1):32-3.

12. Yeh CN, Chen MF, Jan YY. Laparoscopic cholecystectomy in 226 cirrhotic patients. Experience of a single centre in Taiwan. Surg Endosc 2002;16(11):1583-7.

13. Abdullah UY, Jassim HM, Baig AA, Khorsheed RM, Al-khayat AM, Sulong AF, et al. Gallstones in patients with inherited hemolytic diseases. Int J Pharm Pharm Sci 2015;7(7):9-15.

14. Sirinek KR, Burk RR, Brown M, Levine BA. Improving survival in patients with cirrhosis undergoing major abdominal operations. Arch Surg 1987;122:271-3.

15. Lausten SB, El-Sefi T, Marwan I, Ibrahim TM, Jensen LS, Grofte T, 
et al. Postoperative hepatic catabolic stress response in patients with cirrhosis and chronic hepatitis. World J Surg 2000;24(3):365-71.

16. JiW, Li LT, Chen XR, Li JS. Application of laparoscopic cholecystectomy in patients with cirrhotic portal hypertension. Hepatobiliary Pancreat Dis Int 2004;3(2):270-4.

17. Thompson MH, Benger JR. Cholecystectomy, conversion and complications. HPB Surg 2000;11(6):373-8.
18. Fuchs KH. Minimally invasive surgery. Endoscopy 2002;34(2):154-9.

19. Child CG, Turcotte JG. Surgery and portal hypertension. In: Child CG, editor. The Liver and Portal Hypertension. Philadelphia, PA: WB Saunders; 1964. p. 50

20. Muslim Z, Arifin H, Zubir N. Comparative effects of spironolactone and combination with furosemide of ascites fluid and blood electrolyte in cirrhosis. Int J Pharm Pharm Sci 2015;7(8):176-9. 